\title{
Morphological variations of the winged pearl oyster Pteria penguin (Roding, 1798) from South China Sea
}

\author{
HUAYANG GUO*, DIANCHANG ZHANG, SHIGUI JIANG, YOUNING LI, NAN ZHANG, \\ YU WANG AND ZHENHUA MA* \\ South China Sea Fisheries Research Institute, Chinese Academy of Fishery Sciences, Guangzhou - 510 300, P. R. China \\ ${ }^{*}$ Key Laboratory of South China Sea Fishery Resources Exploitation and Utilisation, Ministry of Agriculture \\ Guangzhou - 510 300, P. R. China \\ e-mail: zhenhua.ma@hotmail.com
}

\begin{abstract}
The present study was undertaken to evaluate the morphological variations of Pteria penguin (Roding, 1798) in wild as well as cultured populations from South China Sea. A total of 307 samples were collected from five different geographic locations comprising three wild (Pop. 1, 2 and 4) and two cultured (Pop. 3 and 5) populations and 10 measured traits were analysed. Principal component analysis (PCA), discriminant analysis and cluster analysis were used to evaluate the morphological variations in the collected samples. Results showed a low intra-population variation within the five sampled populations. Multivariate analyses indicated that the five populations were more or less differentiated on the basis of body characters, particularly those related to major dimensions of the shell outline and their ratios. Discriminant analysis revealed that the overall random assignment of individuals into their original groups was high (81.8\%), indicating that these populations are highly divergent from each other. The proportion of individuals correctly classified into their original groups was 96.9, 76.7, 75.0, 78.0 and $82.0 \%$ for populations 1, 2, 3, 4 and 5 respectively. Cluster analysis showed highest morphological variation between Pop.1 and Pop. 2. All other populations (Pop.3, Pop.4 and Pop.5) were found to be morphologically similar and consistent with the respective geographical location. Results of the present study will be of use in resource assessment and management of P. penguin in the South China Sea.
\end{abstract}

Keywords: Geographical populations, Morphometric variation, Multivariate analysis, Pteria penguin

\section{Introduction}

Morphological variation is considered as one of the basic characteristics to assess the population differences in aquatic organisms. Measurement, description and analysis of the morphological variations are fundamental steps to answer questions of biological adaptability ( $\mathrm{Ge}$ and Hong, 1995). Due to genetic differences or environmental factors, morphological characters of aquatic animals are often varying along with geographic gradient among wide-ranged coastal marine animals (Tzeng et al., 2001; O'Reilly and Horn, 2004; Murta et al., 2008). Intra-specific variation in animals is usually regarded as the adaptive mechanism to different environments (Orensanz et al., 1991; Cadrin, 2000; Tzeng et al., 2001; Marquez et al., 2010). Studies on the morphological variations of target species can reveal the dynamics of populations and such information can be used to design management strategies (Orensanz et al., 2005). As one of the solid evaluation parameters, morphological variation has been widely used in population studies (Murta, 2000; Tzeng et al., 2001; Chen et al., 2010), stock discrimination (Cadrin et al., 2005; Turan et al., 2006; Murta et al., 2008) and bio-geographical evaluation (Von et al., 2005). In molluscs, shell shape variation has been reported to distinguish species of similar shape (Innes and Bates, 1999; Aguirre et al., 2006; Rufino et al., 2006; Costa et al., $2008,2010)$ or to analyse intra-specific variation along a wide geographical range (Palmer et al., 2004; Krapivka et al., 2007; Marquez et al., 2010).

The winged pearl oyster Pteria penguin (Roding, 1798) (family: Pteriidae), is widely distributed in Western Pacific Ocean and Indian Ocean (Southgate et al., 2008). In South China, $P$. penguin is traditionally used for production of half-pearls ('mabé'). P. penguin is considered as an important pearl oyster species in Guangdong, Guangxi and Hainan provinces of China due to its high economic value (Qi et al., 2011). Recently, as consequence of overfishing and habitat deterioration, the natural availability of $P$. penguin has reduced significantly. Moreover, the germplasm resources of $P$. penguin has changed considerably due to the long-term culture of the species without proper 
germplasm management. Therefore, it is necessary to formulate effective germplasm management strategies for $P$. penguin. Recent sudies on $P$. penguin focused on aspects like hatchery production (Teitelbaum et al., 2008; Mattew and Southgate., 2012), biofouling (Guenther and De Nys, 2006), polychaete verminosis (Liang et al., 2007), pearl production (Kripa et al., 2008; Kishore et al., 2013), pearl shell lectin (Naganuma et al., 2006), gametogenic process (Arjarasirikoon et al., 2004) and Pteria toxins (Takada et al., 2001). Information on the morphological variations in $P$. penguin has not been reported so far. In the present study, 10 morphological characters of $P$. penguin within five established populations from the South China Sea were analysed with the objective of estimating morphometric variability among different populations.

\section{Materials and methods}

A total 307 samples of $P$. penguin were collected from three wild populations, from Sanya Bay, Beihai Bay and Lingao Bay (designated as Pop. 1, Pop. 2 and Pop. 4 respectively) and two cultured populations (from Xuwen Bay and Li' an designated as Pop. 3 and Pop. 5 respectively) in the South China Sea during October 2013 and June 2014 (Fig. 1, Table 1). All samples were transported live in cool moist condition to the Tropical Fisheries Rresearch and Development Center, South China Sea Fisheries Research Institute, Hainan Province, P. R. China. The samples were scrubbed and washed thoroughly in seawater to remove the fouling organisms and silt, before taking morphometric measurements. Morphometric measurements were taken using a digital vernier caliper (Hangzhou) accurate to $0.01 \mathrm{~mm}$. A total of 5 landmarks and 7 distances were measured (Fig. 2). These landmarks were selected based on the shell structure of $P$. penguin. Further, those landmarks which can be easily observed and assessed by naked eye were selected (Nie et al., 2013). In addition to these, shell length (SL), shell height (SH) and shell width (SW) were also recorded. Linoy Libini et al. (2011) reported that the

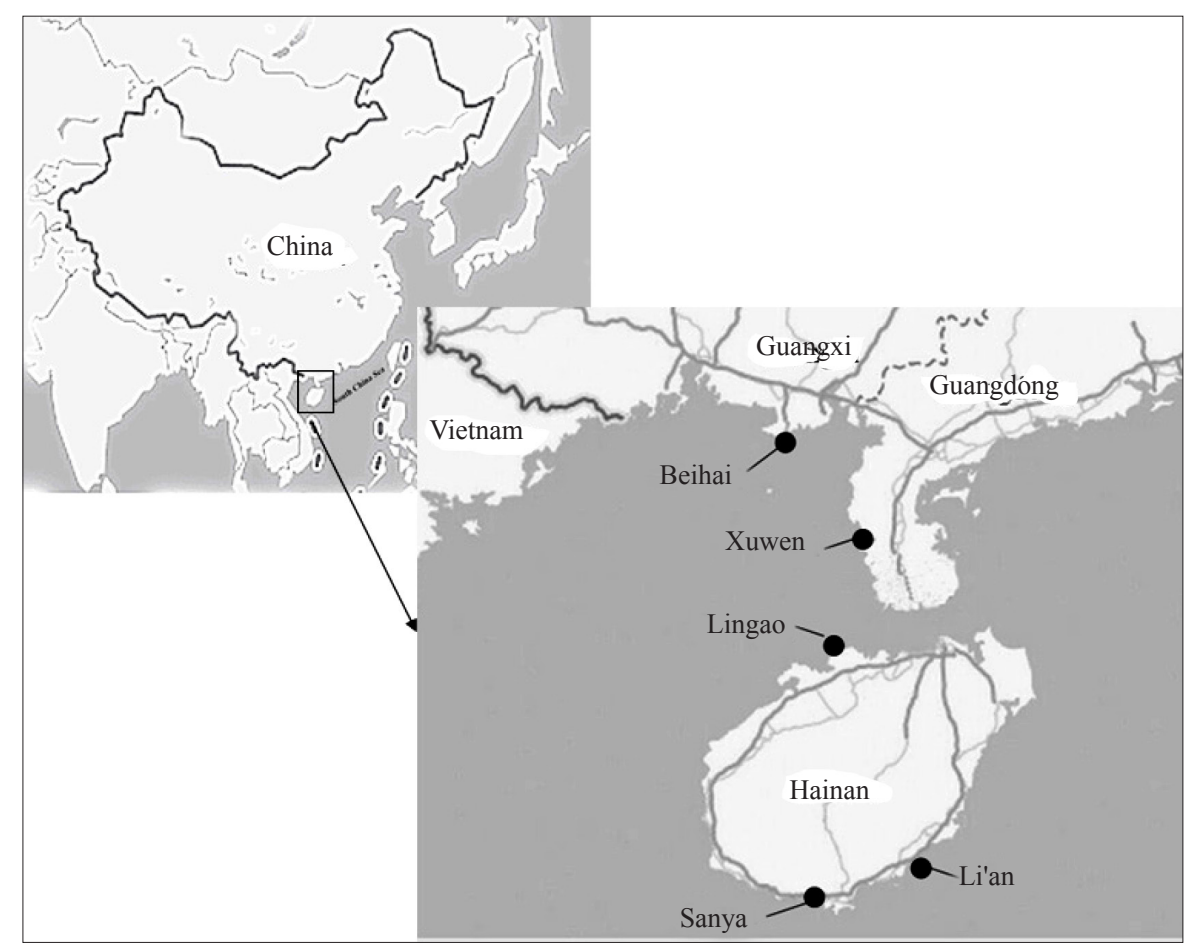

Fig. 1. Map showing the location of study sites ( $\bullet$ : sampling sites)

Table 1. Sampling details of $P$. penguin used in the study

\begin{tabular}{|c|c|c|c|}
\hline Populations & Locality & Geographic coordinates & Sample size \\
\hline Pop. 1 & Sanya, Hainan Province, China & $18^{\circ} 25^{\prime} \mathrm{N}, 109^{\circ} 39^{\prime} \mathrm{E}$ & 65 \\
\hline Pop. 2 & Beihai, Guangxi Province, China & $21^{\circ} 07^{\prime} \mathrm{N}, 109^{\circ} 11^{\prime} \mathrm{E}$ & 90 \\
\hline Pop. 3 & Lingao, Hainan Province, China & $20^{\circ} 04^{\prime} \mathrm{N}, \quad 109^{\circ} 63^{\prime} \mathrm{E}$ & 52 \\
\hline Pop. 4 & Lingshui, Hainan Province, China & $18^{\circ} 43^{\prime} \mathrm{N}, \quad 110^{\circ} 06^{\prime} \mathrm{E}$ & 50 \\
\hline Pop. 5 & Xuwen, Guangdong Province, China & $20^{\circ} 43^{\prime} \mathrm{N}, \quad 109^{\circ} 94^{\prime} \mathrm{E}$ & 50 \\
\hline
\end{tabular}

Pop. = Population 


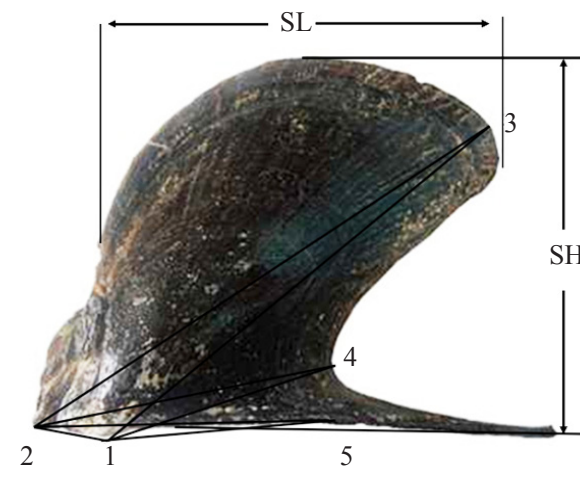

(a)

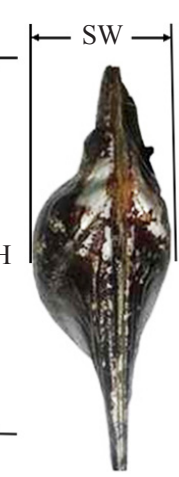

(b)
Fig. 2. Profile of $P$. penguin showing details of morphometric measurements taken on each individual (right shell in the upper side)

SL: shell length; SH: shell height; SW: shell width; Locations of the other 8 landmarks for constructing the truss network are illustrated as numbers and morphometric distance measures between the dots as lines

hinge length in P. penguin becomes an unreliable measure, as the posterior ear tips are often broken during collection. Therefore, only samples with undamaged shell, except the posterior ear tips were included and analysed in this study.

Statistical analyses were performed with SPSS 13.0 software (SPSS Inc., Chicago, USA). To remove the effect of size and age, all morphometric characters were standardised according to the equation $\mathrm{L}_{\mathrm{S}}=\mathrm{L} / \mathrm{SL}$, where $\mathrm{Ls}=$ standardised measurement, $\mathrm{L}=$ measure traits and $\mathrm{SL}=$ shell length of each specimen (Wang et al., 2009).

Descriptive statistics including mean (X), standard deviation (SD) and coefficient of variation $(\mathrm{CV}=\mathrm{SD} / \mathrm{X})$ of each morphological character within and among populations were calculated using EXCEL 2003 (Microsoft Corporation, Redmond, WA, USA).

Principal component, discriminant factorial and hierarchical cluster analyses were used in this study. Principle component analysis (PCA) was used to reduce the amount of morphometric data and evaluate morphometric variation among specimens and to identify variables responsible for this (Veasey et al., 2001; Samaee et al., 2006, 2009). All PCAs with Eigen value $>1$ were considered as important (Chatfield and Collins, 1983). Use of the correlation matrix in PCA, in this study, allowed a direct interpretation of character loadings $(>0.80)$ and a direct comparison between populations.

Discriminant function analysis (DFA) was conducted to test the effectiveness of the characters in predicting different group locations, which clarify the relative importance of such traits as discriminators between a priori for groups, as performed by Kong et al. (2007) and Konan et al. (2010). A forward stepwise function analysis was carried out to reduce the number of variables (Jain et al., 2000; Poulet et al., 2004; 2005) and to identify the combinations of variables which separate groups (Hair et al., 1996). The classification success rate was evaluated based on the percentage of individuals correctly assigned in to original sample (Silva, 2003; Marques et al., 2006). The relative importance of meristic and morphometric characters in discriminating populations was assessed using the F-to-remove statistic (F-to-enter, 3.84; F-to-remove, 2.71) (Turan et al., 2006). A complement to discriminant analysis i.e., hierarchical cluster analysis (HCA) based on Euclidean nearest neighbour was used to test whether there was any correlation between morphological and geographical distances (Turan et al., 2006; Ferrito et al., 2007).

\section{Results and discussion}

The present study aimed to assess the morphological variations in different geographic populations of $P$. penguin in South China Sea. The parameters of measured traits are given in Table 2. The coefficients of variation $(\mathrm{CVs})$ of most measured traits from Pop.1 were higher than the other four populations. The highest CVs of D (1-2) was obtained in Pop. 4 (19.82\%), while the lowest value (4.18\%) was recorded in D (1-3) from Pop. 3. The CVs of all measured traits from five different populations were relatively low $(\mathrm{CV}<20 \%$, Table 2). Results from the present study showed that intra-population variation in morphometric characters were found to be low for the five geographic populations tested. This was proved by low values of coefficient of variation $(\mathrm{CV}<20 \%)$ for all measured variables and justified that a phenotypically homogeneous group was there within each population (Ferrito et al., 2007; Konan et al., 2010). Recent reports indicated that low values of CV may justify high inheritability (Mamuris et al., 1998) and consequently limited influence of environmental variation on morphological variability (Soule and Cuzin-Roudy, 1982). Results of the present study indicated that all the five populations were with low variation and morphologically not much influenced by environmental conditions.

The results of PCA showed that a total of $68 \%$ of the total variation associated with the 10 morphometric characters were accounted for the first two principal components in the tested populations, which explain the variability manifested between individuals (Table 3 ). The characteristics with an Eigen vector of $>0.80$ were included and the others discarded. PC1 loadings explained $53.84 \%$ of the total variations, while only 
Table 2. Descriptive statistics of various morphological characters within five populations of $P$. penguin

\begin{tabular}{|c|c|c|c|c|c|c|}
\hline \multicolumn{2}{|l|}{ Variable } & \multirow{2}{*}{$\begin{array}{l}\text { Pop. } 1 \\
127.21 \pm 14.44\end{array}$} & \multirow{2}{*}{$\begin{array}{l}\text { Pop. } 2 \\
120.11 \pm 9.56\end{array}$} & \multirow{2}{*}{$\begin{array}{l}\text { Pop. } 3 \\
93.26 \pm 6.59\end{array}$} & \multirow{2}{*}{$\begin{array}{l}\text { Pop. } 4 \\
89.57 \pm 5.73\end{array}$} & \multirow{2}{*}{$\begin{array}{l}\text { Pop. } 5 \\
90.11 \pm 5.34\end{array}$} \\
\hline$\overline{\mathrm{SL}}$ & Mean \pm SD & & & & & \\
\hline & Range & $82.24-162.60$ & $91.16-145.5$ & $73.52-126.21$ & $74.42-104.41$ & 74.31-104.46 \\
\hline & CV (\%) & 11.35 & 7.96 & 7.07 & 6.40 & 5.92 \\
\hline \multirow[t]{3}{*}{ SH } & Mean \pm SD & $175.04 \pm 18.85$ & $155.32 \pm 12.38$ & $114.48 \pm 5.94$ & $110.16 \pm 6.81$ & $113.05 \pm 7.90$ \\
\hline & Range & $175.04-225.08$ & $115.16-190.00$ & $97.85-129.11$ & $92.39-131.05$ & $86.31-162.60$ \\
\hline & CV (\%) & 10.77 & 7.97 & 5.19 & 6.18 & 6.99 \\
\hline \multirow[t]{3}{*}{ SW } & Mean \pm SD & $54.9 \pm 5.79$ & $62.09 \pm 4.11$ & $45.75 \pm 2.98$ & $49.62 \pm 3.09$ & $46.65 \pm 2.77$ \\
\hline & Range & $23.37-71.23$ & $51.32-77.22$ & $37.98-51.89$ & $36.30-57.34$ & $39.43-56.12$ \\
\hline & CV (\%) & 10.54 & 6.62 & 6.50 & 6.22 & 5.94 \\
\hline \multirow[t]{3}{*}{$\mathrm{D}(1-3)$} & Mean $\pm \mathrm{SD}$ & $231.86 \pm 23.90$ & $204.80 \pm 15.73$ & $142.60 \pm 5.96$ & $139.46 \pm 7.82$ & $140.95 \pm 8.32$ \\
\hline & Range & $157.55-285.99$ & $155.05-250.82$ & $122.61-174.44$ & $120.02-160.55$ & $115.43-173.12$ \\
\hline & CV (\%) & 10.31 & 7.68 & 4.18 & 5.60 & 5.90 \\
\hline \multirow[t]{3}{*}{ D (1-4) } & Mean \pm SD & $112.06 \pm 9.56$ & $105.32 \pm 10.25$ & $78.82 \pm 5.16$ & $84.57 \pm 5.71$ & $79.97 \pm 4.09$ \\
\hline & Range & $88.00-133.31$ & $81.45-238.40$ & $66.23-121.52$ & $69.88-101.60$ & $70.29-90.48$ \\
\hline & CV (\%) & 8.53 & 9.73 & 6.55 & 6.75 & 5.11 \\
\hline \multirow[t]{3}{*}{$\mathrm{D}(2-3)$} & Mean $\pm \mathrm{SD}$ & $250.29 \pm 24.45$ & $221.15 \pm 16.33$ & $153.53 \pm 6.66$ & $149.04 \pm 9.25$ & $149.28 \pm 8.03$ \\
\hline & Range & $170.60-250.29$ & $167.47-273.47$ & 132.37-187.09 & $129.38-170.23$ & $130.31-180.07$ \\
\hline & CV (\%) & 9.77 & 7.38 & 4.34 & 6.21 & 5.38 \\
\hline \multirow[t]{3}{*}{ D (2-4) } & Mean \pm SD & $137.77 \pm 12.08$ & $124.26 \pm 8.86$ & $95.95 \pm 6.90$ & $97.02 \pm 7.46$ & $90.66 \pm 4.30$ \\
\hline & Range & $105.97-168.38$ & $94.24-146.99$ & $77.64-150.31$ & $80.51-122.07$ & $79.83-103.71$ \\
\hline & CV (\%) & 8.77 & 7.13 & 7.20 & 7.69 & 4.74 \\
\hline \multirow{3}{*}{$\mathrm{D}(1-2)$} & Mean $\pm \mathrm{SD}$ & $30.42 \pm 5.52$ & $30.02 \pm 3.96$ & $19.38 \pm 3.60$ & $17.50 \pm 3.47$ & $14.12 \pm 1.93$ \\
\hline & Range & $12.91-47.88$ & $16.28-40.02$ & $8.76-27.79$ & $9.80-26.35$ & $8.51-18.88$ \\
\hline & CV (\%) & 18.13 & 13.20 & 18.59 & 19.82 & 13.68 \\
\hline \multirow[t]{3}{*}{$\mathrm{D}(1-5)$} & Mean $\pm \mathrm{SD}$ & $108.13 \pm 9.39$ & $107.46 \pm 12.47$ & $87.98 \pm 7.46$ & $81.33 \pm 5.51$ & $78.44 \pm 4.51$ \\
\hline & Range & $84.12-131.73$ & $81.12-149.54$ & $40.09-109.74$ & $68.15-99.84$ & $63.20-89.82$ \\
\hline & CV (\%) & 8.69 & 11.61 & 8.48 & 6.78 & 5.75 \\
\hline \multirow[t]{3}{*}{$\mathrm{D}(2-5)$} & Mean $\pm \mathrm{SD}$ & $136.76 \pm 11.89$ & $125.77 \pm 9.4$ & $84.87 \pm 10.81$ & $95.76 \pm 7.39$ & $88.61 \pm 4.20$ \\
\hline & Range & $107.39-163.25$ & $101.28-155.00$ & $62.14-115.70$ & $78.55-122.67$ & $78.08-100.90$ \\
\hline & CV (\%) & 8.70 & 7.47 & 12.74 & 7.71 & 4.74 \\
\hline
\end{tabular}

D (number a - number b): Distance between two landmarks; SL: Shell length; SH: Shell height; SW: Shell width; SD: Standard deviation; CV: Coefficient of variation; Pop.: Population

Table 3. Contributive proportion and loading of principal components on the morphological characteristics of $P$. penguin

\begin{tabular}{lll}
\hline \multirow{2}{*}{ Characters } & \multicolumn{2}{c}{ Principal components } \\
\cline { 2 - 3 } & 1 & 2 \\
\hline $\mathrm{SH} / \mathrm{SL}$ & 0.394 & 0.070 \\
$\mathrm{SW} / \mathrm{SL}$ & 0.480 & 0.604 \\
$\mathrm{D}(1-3) / \mathrm{SL}$ & $0.764^{*}$ & 0.060 \\
$\mathrm{D}(1-4) / \mathrm{SL}$ & $0.915^{*}$ & -0.178 \\
$\mathrm{D}(2-3) / \mathrm{SL}$ & $0.796^{*}$ & -0.098 \\
$\mathrm{D}(2-4) / \mathrm{SL}$ & $0.941^{*}$ & 0.036 \\
$\mathrm{D}(1-2) / \mathrm{SL}$ & 0.151 & $0.871^{*}$ \\
$\mathrm{D}(1-5) / \mathrm{SL}$ & $0.823^{*}$ & -0.327 \\
$\mathrm{D}(2-5) / \mathrm{SL}$ & $0.906^{*}$ & -0.02 \\
Eigen value & 4.845 & 1.282 \\
Variance (\%) & 53.837 & 14.239 \\
Cumulative variance (\%) & 53.837 & 68.076 \\
\hline
\end{tabular}

"Indicates that loading value exceeds 0.75 ; D (number a - number b): Distance between two landmarks; SL: Shell length; SH: Shell height; SW: Shell width.
$14.24 \%$ of the total variation was explained by PC 2 (Table 3). PC 1 of the analysis was related to major dimensions of shell outline, including $\mathrm{D}(1-3) / \mathrm{SL}$, $\mathrm{D}(1-4) / \mathrm{SL}, \mathrm{D}(2-3) / \mathrm{SL}, \mathrm{D}(2-4) / \mathrm{SL}$ and some traits of shell hinge, such as $\mathrm{D}(1-5) / \mathrm{SL}$ and $\mathrm{D}(2-5) / \mathrm{SL}$. In PC 1 , the most important character was $\mathrm{D}(2-4) / \mathrm{SL}$, with contribution of $94.1 \%, \mathrm{D}(1-4) / \mathrm{SL}$ followed with the value of $91.5 \%$. The traits loading on $\mathrm{PC} 2$ was only intensively related to the anterior ear tips and D (1-2)/SL had the maximum contribution (87.1\%). Recent studies have reported that dorso-ventral traits are used as a measure of growth index for $P$. penguin (Linoy Libini et al., 2011; Milione and Southgate, 2011, 2012), which indicated that the major morphological characters for the bivalves reflect both phylogenetic history and life habits (Gordillo et al., 2014). The scores of visual examination of the plots through PC1 and PC2 are presented in Fig. 3. All populations were located in the middle group of the first PC and the second PC 
(Fig. 3). The shell shape traits used in the present study have shown to provide an insight into the discrimination of different populations of of $P$. penguin.

Discriminant function analysis (DFA) could be a useful method to distinguish different stocks of the same species (Murta et al., 2008). In the present study, the DFA of morphometric characters produced four functions, which explained $100 \%$ of the accumulated population variance (Table 4). It was found that $87.9 \%$ of the total variance was contributed by the first and second canonical variables $(67.80 \%$ and $20.10 \%$ respectively) indicating that the greatest proportion of the total variance was due to the first two canonical variables (Table 4). The stepwise discriminant analysis retained seven variables

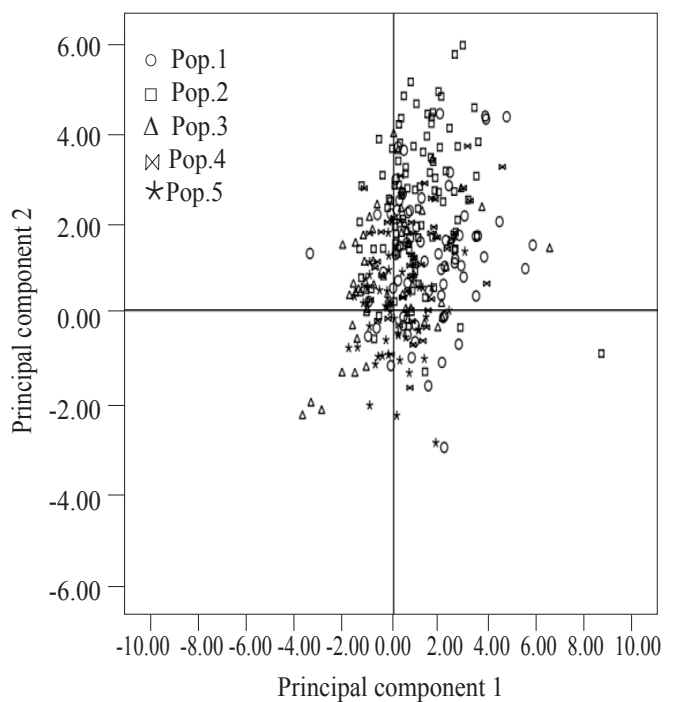

Fig. 3. Scatter plot of principal components from the principal components analysis of different populations of $P$. penguin that are most discriminant among the different populations (Table 5). These characters of primary importance in distinguishing among the five populations where $\mathrm{D}(2-3) \quad(\lambda=0.52 ; \mathrm{F}=71.23 ; \mathrm{p}<0.001), \mathrm{SW}(\lambda=0.237$; $\mathrm{F}=79.38 ; \mathrm{p}<0.001), \mathrm{D}(1-2)(\lambda=0.179 ; \mathrm{F}=60.55 ; \mathrm{p}<0.001)$, $\mathrm{D}(2-5)(\lambda=0.128 ; \mathrm{F}=54.90 ; \mathrm{p}<0.001), \mathrm{D}(1-5)(\lambda=0.085$; $\mathrm{F}=54.37 ; \quad \mathrm{p}<0.001), \quad \mathrm{D}(2-4) \quad(\lambda=0.070 ; \quad \mathrm{F}=49.25$; $\mathrm{p}<0.001)$ and $\mathrm{SH} \quad(\lambda=0.066 ; \quad \mathrm{F}=42.81 ; \quad \mathrm{p}<0.001)$. Summary statistics indicated that the coefficients SW/SL (D (1-2)/SL and D (2-5)/SL) contributed the most to the first 2 discriminant functions, respectively (Table 6). Based on DFA evaluation, the overall random assignment of individuals into their original groups was $81.8 \%$ (Table 7 ), which indicate a high degree of inheritance between populations in shell morphology in the study area. The most well-defined population was found to be Pop.1 with classified individual percentage of $96.90 \%$ (Table 7), followed by Pop. 5 (82\%) and Pop. 4 (78\%). The incorrect percentages in five populations ranged from 2 to $18 \%$ and the majority of misclassification proportion (18\%) of Pop. 4 has morphometric characters similar to Pop. 5 (Table 7). In addition, only a proportion of $3.1 \%$ of Pop.1 was allocated to Pop. 2 and only $4.4 \%$ of Pop. 2 was classified as Pop. 1. The confusion matrix ranged from $13.5-18 \%$ and the misclassification proportion among Pop. 3, Pop. 4 and Pop. 5 were high. The scatter plots of DFA scores for the study are showed in Fig. 4. Visual examination of the plots of DFA 1 and DFA 2 scores indicated that selected samples are grouped into five major respective areas. This explained the efficiency of discriminator power of morphometric characters used. Indeed, a strong discriminating power of the morphometric variables was found for comparison

Table 4. Statistical analysis of first three discriminant functions for the ratios of the populations of $P$. penguin

\begin{tabular}{lllllll}
\hline Function & Value & Variance (\%) & Cumulative variance (\%) & Chi Square & DF & p \\
\hline 1 & 3.450 & 67.80 & 67.8 & 813.56 & 365.66 & 28 \\
2 & 1.020 & 20.10 & 87.9 & 154.67 & $<0.001$ \\
3 & 0.497 & 9.80 & 97.7 & 33.60 & $<0.001$ & 10 \\
4 & 0.119 & 2.30 & 100 & $<0.001$ & 4 \\
\hline
\end{tabular}

DF: Degrees of freedom; p: Probability value

Table 5. Discriminatory power of morphometic characters of individuals of $P$. penguin retained by step discriminant analysis

\begin{tabular}{lllll}
\hline Variables & Wilk Lambda $(\lambda)$ & F to enter/remove & Probability & Tolerance \\
\hline SH/SL & 0.070 & 42.805 & $* * *$ & 0.615 \\
SW/SL & 0.237 & 79.384 & $* * *$ & 0.698 \\
$\mathrm{D}(2-3) / \mathrm{SL}$ & 0.515 & 71.230 & $* * *$ & 0.371 \\
$\mathrm{D}(2-4) / \mathrm{SL}$ & 0.070 & 49.253 & $* * *$ & 0.437 \\
$\mathrm{D}(1-2) / \mathrm{SL}$ & 0.179 & 60.546 & $* * *$ & 0.649 \\
$\mathrm{D}(1-5) / \mathrm{SL}$ & 0.085 & 54.367 & $* * *$ & 0.528 \\
$\mathrm{D}(2-5) / \mathrm{SL}$ & 0.128 & 54.902 & & 0.348 \\
\hline
\end{tabular}

${ }^{* * *} \mathrm{p}<0.001$; D (number a - number b): Distance between two landmarks; SL: Shell length; SH: Shell height; SW: Sshell width 
Table 6. Morphometric variables for $P$. penguin obtained using Wilk discriminant function

\begin{tabular}{lllll}
\hline \multirow{2}{*}{ Characters } & \multicolumn{4}{c}{ Function } \\
\cline { 2 - 5 } & 1 & 2 & 3 & 4 \\
\hline SH & 1.698 & 0.701 & -4.976 & -0.588 \\
SW & -17.137 & -7.373 & 13.948 & -3.464 \\
D23 & 7.316 & -0.619 & 3.98 & -4.613 \\
D24 & -2.524 & 3.311 & -8.258 & 10.427 \\
D12 & 8.126 & 15.454 & 14.527 & 10.708 \\
D15 & -3.673 & 8.476 & -0.814 & -1.23 \\
D25 & 0.758 & -14.697 & -0.202 & 1.609 \\
Constant & -3.203 & 4.57 & -1.246 & -3.131 \\
\hline
\end{tabular}

Geographically, Beihai (Pop. 2), Lin'gao (Pop. 4) and Xunwen (Pop. 3) populations were found closer, while a shorter geographical distance was observed between Sanya (Pop. 1) and Lingshui (Pop. 5) (Fig. 1). Hierarchical cluster analysis revealed that the studied populations were clustered into two distinct groups (Fig. 5), demonstrating that there might be considerable morphological divergence among different geographical groups. This result indicated that Xuwen (Pop. 3), Lin'gao (Pop. 4) and Li'an (Pop. 5) populations are geographically close. The results speculated that the

Table 7. Results of the number of individuals classified and the percent in each group

\begin{tabular}{|c|c|c|c|c|c|c|c|}
\hline & \multirow{2}{*}{ Populations } & \multicolumn{6}{|c|}{ Predicted group membership } \\
\hline & & Pop. 1 & Pop. 2 & Pop. 3 & Pop. 4 & Pop. 5 & Total \\
\hline \multirow[t]{5}{*}{ Original grouping } & Pop. 1 & 63 & 2 & 0 & 0 & 0 & 65 \\
\hline & Pop. 2 & 4 & 69 & 7 & 5 & 5 & 90 \\
\hline & Pop. 3 & 0 & 5 & 39 & 1 & 7 & 52 \\
\hline & Pop. 4 & 0 & 2 & 0 & 39 & 9 & 50 \\
\hline & Pop. 5 & 0 & 1 & 0 & 8 & 41 & 50 \\
\hline \multirow[t]{5}{*}{ Percentage (\%) } & Pop. 1 & 96.9 & 3.1 & 0 & 0 & 0 & 100 \\
\hline & Pop. 2 & 4.4 & 76.7 & 7.8 & 5.6 & 5.6 & 100 \\
\hline & Pop. 3 & 0 & 9.6 & 75 & 1.9 & 13.5 & 100 \\
\hline & Pop. 4 & 0 & 4 & 0 & 78 & 18 & 100 \\
\hline & Pop. 5 & 0 & 2 & 0 & 16 & 82 & 100 \\
\hline
\end{tabular}

A: $81.8 \%$ of original grouped cases correctly classified; Pop. : Population

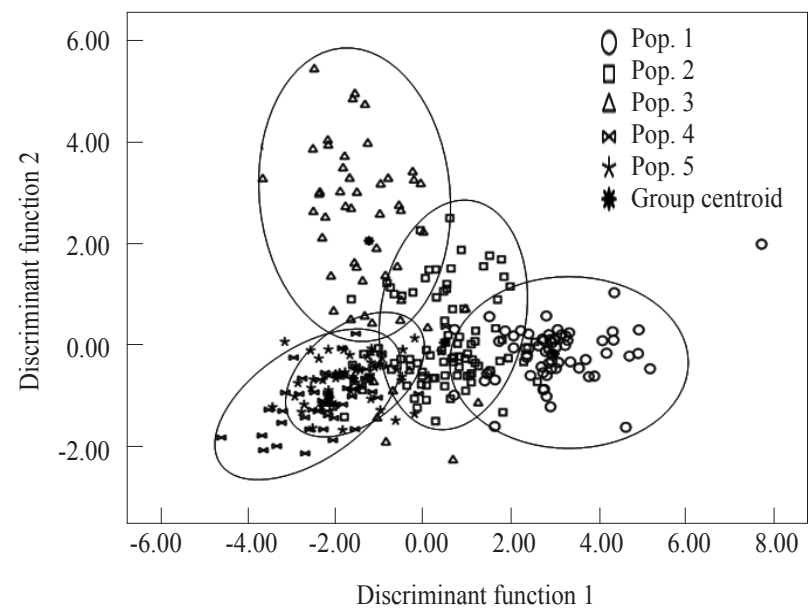

Fig. 4. Scatter diagram for discriminant function 1 and discriminant function 2 of $P$. penguin from five different geographical populations

between populations (Murta, 2000; Garcia-Davila et al., 2005; Ferrito et al., 2007; Anastasiadou and Leonardos, 2008; Anastasiadou et al., 2009). The differences found among the shape of shells could also be explained as the outcome of the phenotypic plasticity of the populations subjected to different environmental conditions (Marquez et al., 2010).

$\begin{array}{lrrrrrr}\text { C A S E } & 0 & 5 & 10 & 15 & 20 & 25 \\ \text { Label Number } & +----------+----------+---------++----------+----------+\end{array}$

Pop. 3

Pop. $5 \sqcup$

Pop. 4

Pop. 1

Pop. 2

Fig. 5. Dendrogram of $P$. penguin populations based on morphological characters

source of Li'an culture population might be Xuwen Bay. Sanya (Pop.1) and Beihai (Pop. 2) populations clustered into one group and the divergent distance between Pop. 1 and Pop. 2 was significantly greater than the other populations (Fig. 5). The discriminant analysis also confirmed above results, which showed that the incorrect percentages between Pop. 1 and Pop. 2 were $<5 \%$ (Table 7). Recent study showed that the expression of phenotype is largely determined by the environment of the habitat (Brian et al., 2006). But the causes of morphological differences among populations are often quite difficult to be explained (Poulet et al., 2004). Variation in morphometric characters may be affected by genetic and environmental factors (Murta, 2000). 
Although it is possible to suggest how variations in shell morphology of $P$. penguin could be adaptive in different environments, it is difficult to tease apart the possible explanations due to the complexity of the relationship between phenotype and the local physical and ecological conditions. Further verification of the stock structure may be essential by biological evidence, such as geometric morphometry and genomic analyses.

In this study, the shape analysis proved to be a powerful tool for stock discrimination of $P$. penguin in the South China Sea, representing this species with high probability of interbreeding. The present study demonstrates that five populations of $P$. penguin from different areas of the South China Sea are more or less discriminated on the basis of shape measurements related to $\mathrm{D}(1-4)$ and $\mathrm{D}(2-4)$. Results from the present study provide valuable information on the population identification of $P$. penguin in the South China Sea which can facilitate the development of management strategies, the design of biological sampling programs and strategies for conserving diversity of this species.

\section{Acknowledgements}

This project was funded by Central Institute of Public Welfare Projects (2012TS18), Major Science and Technology Projects of Guangdong (A201201A03), Special Scientific Research Funds for Central Non-profit Institutes, Chinese Academy of Fishery Sciences (2013A07XK02), Key Scientific and Technological Projects of Hainan (ZDXM20120032), Social Development in Science and Technology Projects of Hainan (2011SF014) and Supporting Project of Sanya City (2013PT13). Authors are grateful to all the laboratory staff for the technical support.

\section{References}

Aguirre, M. L., Perez, S. I. and Sirch, Y. N. 2006. Morphological variability of Brachidontes swainson (Bivalvia Mytilidae) in the marine Quaternary of Argentina (SW Atlantic). Palaeogeogr. Palaeocl., 239: 100-125.

Anastasiadou, C. and Leonardos, I. D. 2008. Morphological variation among populations of Atyaephyra desmarestii (Millet, 1831) (Decapoda: Caridea: Atyidae) from freshwater habitats of north-western Greece. J. Crustacean Biol., 28: 240-247.

Anastasiadou, C., Liasko, R. and Leonardos, I. D. 2009. Biometric analysis of lacustrine and riverine populations of Palemonetes antennarius (H. Milne-Edwards, 1837) (Crustacea, Decapoda, Palaemonidae) from north-western Greece. Limnologica-Ecology Manag. Inland Waters, 39: $244-254$.

Arjarasirikoon, U., Kruatrachue, M., Sretarugsa, P., Chitramvong, Y., Jantateme, S. and Upatham, E. S. 2004.
Gametogenic processes in the pearl oyster, Pteria penguin (Roding, 1798) (Bivalvia, Mollusca). J. Shellfish Res., 23: 403-409.

Brian, J. V., Fernandes, T., Ladle, R. J. and Peter, A. T. 2006. Patterns of morphological and genetic variability in UK populations of shore crab, Carcinus maenas Linnaeus, 1758 (Crustacea: Decapoda: Brachyura). J. Exp. Mar. Biol. Ecol., 329: 47-54.

Cadrin, S. X. 2000. Advances in morphometric analysis of fish stock structure. Rev. Fish Biol. Fish., 10: 91-112.

Cadrin, S. X., Friedland, K. D. and Waldman, J. 2005. Stock identification methods: applications in fishery science. Elsevier Academic Press, San Diego, CA. 381 pp.

Chatfield, C. and Collins, A. J. 1983. Introduction to multivariate analysis. Chapmanand Hall, London, 246 pp.

Costa, C., Aguzzi, J., Menesatti, P., Antonucci, F., Rimatori, V. and Mattoccia, M. 2008. Shape analysis of different populations of clams in relation to their geographical structure. J. Zool., 276: 71-80.

Costa, C., Menesatti, P., Aguzzi, J., D’Andrea, S., Antonucci, F., Rimatori, V., Pallottino, F. and Mattoccia, M. 2010. External shape differences between sympatric populations of commercial clams Tapes decussatus and T. philippinarum. Food Bioprocess Tech., 3: 43-48.

Chen, X. H., Gao, Y. B., Zhao, T. T., Zhu, M. J., Ci, H. C. and Song, X. Y. 2010. Morphological variation of Caragana microphylla populations in the Xiling steppe and their relationship with environmental factors. Acta Ecologica Sinica., 30: 50-55.

Dommergues, E., Dommergues, J. L., Magniez, F., Neige, P. and Verrecchia, E. P. 2003. Geometric measurements analysis versus Fourier series analysis for shape characterisation using gastropod shell (Trivia) as an example. Math. Geol., 35: 887-894.

Ferrito, V., Mannino, M. C., Pappalardo, A. M. and Tigano, C. 2007. Morphological variation among populations of Aphanius fasciatus Nardo, 1827 (Teleostei, Cyprinodontidae) from the Mediterranean. J. Fish Biol., 70: $1-20$

Garcia-Davila, C. R., Magalhaes, C. and Guerrero, J. C. H. 2005. Morphometric variability in populations of Palaemonetes spp. (Crustacea, Decapoda, Palaemonidae) from the Peruvian and Brazilian Amazon Basin. Iheringia Serie Zoologia, 95: 327-334.

Ge, S. and Hong, D. Y. 1995. Biosystematic studies on Adenophora potaninii Korsh. complex (Campanulaceae) III. Genetic variation and taxonomic value of morphological characters. Acta Phytotaxon Sin., 33: 433-443.

Gordillo, S., Bayer, M. S., Boretto, G. and Charo, M. 2014 Morphometry In: Gordillo, S., Bayer, M. S., Boretto, G. and Charo, M. (Eds.), Mollusk shells as bio-geo-archives. Springer International Publishing, p. 57-63. 
Guenther, J. and De Nys, R. 2006. Differential community development of fouling species on the pearl oysters Pinctada fucata, Pteria penguin and Pteria chinensis (Bivalvia, Pteriidae). Biofouling, 22: 163-171.

Hair, J. R., Anderson, R., Tatham, R. and Black, W. 1996. Multivariate data analysis with readings. Prentice Hall Incorporated, New Jersey, 729 pp.

Innes, D. J. and Bates, J. A. 1999. Morphological variation of Mytilus edulis and Mytilus trossulus in eastern Newfoundland. Mar Biol., 133: 691-699.

Jain, A. K., Duin, R. P. W. and Mao, J. 2000. Statistical pattern recognition: a review. IEEE Trans. Pattern Anal. Machine Int., 22: 4-37.

Krapivka, S., Toro, J. E., Alcapan, A. C., Astorga, M., Presa, P., Perez, M. and Guinez, R. 2007. Shell-shape variation along the latitudinal range of the Chilean blue mussel. Mytilus chilensis (Hupe 1854). Aquac. Res., 38: 1770-1777.

Kishore, P., Southgate, P. C., Seeto, J. and Hunter, J. 2013. Factors influencing the quality of half-pearls (mabe) produced by the winged pearl oyster, Pteria pengiin (Roding, 1758). Aquac. Res., 46: 1-8.

Konan, K. M., Adepo-Gourene, A. B., Ouattara, A., Nyingy, W. D. and Gourenea, G. 2010. Morphometric variation among male populations of freshwater shrimp Macrobrachium vollenhovenii Herklots, 1851 from Cote d'Ivoire River. Fish. Res., 103: 1-8.

Kong, L., Li, Q. and Qiu, Z. 2007. Genetic and morphological differentiation in the clam Coelomactra antiquata (Bivalvia: Veneroida) along the coast of China. J. Exp. Mar. Biol. Ecol., 343: 110-117.

Kripa, V., Abraham, K., Libini, C., Velayudhan, T. S., Radhakrishnan, P., Mohamed, K. S. and Modayil, M. J. 2008. Production of designer mabe pearls in the black-lipped pearl oyster, Pinctada margaritifera and the winged pearl oyster, Pteria penguin from Andaman and Nicobar Islands, India. J. World Aquac. Soc., 39: 131-137.

Liang, F., Liu, Y., Deng, C. and Mao, Y. 2007. Survey on polychaete vermionsis in farmed pearl oyster (Pteria penguin) in Liusa Bay, Leizhou, Guangdong. Mar. Fish. Res., 28: 84-89.

Linoy Libini, C., Abraham, K. J., Shanmugam, K., Prash Rao, K., Kripa, V., Velayudhan, T. S. and Mohamed, K. S. 2011. Biometric relationships of the black winged pearl oyster, Pteria penguin (Roding, 1798) from Andaman and Nicobar Islands. Indian J. Fish., 58: 139-143.

Mamuris, Z., Apostolidis, P., Panagiotaki, P., Theodorou, A. J. and Triantaphyllidisdir, C. 1998. Morphological variation between red mullet populations in Greece. J. Fish Biol., 52: 107-117.

Mattew, W. and Southgate, P. C. 2012. Effects of settlement cues on behaviour and substrate attachment of hatchery reared winged pearl oyster (Pteria penguin) larvae. Aquaculture, 344-349: 216-222.
Marquez, F., Robledo, J., Penaloza, G. E. and Molen, S. V. 2010. Use of different geometric morphometrics tools for the discrimination of phenotypic stocks of the striped clam Ameghinomya antiqua (Veneridae) in North Patagonia, Argentina. Fish. Res., 101: 127-131.

Murta, A. G. 2000. Morphological variation of horse mackerel (Trachurus trachurus) in the Iberian and North African Atlantic: implications for stock identification. ICES J. Mar. Sci., 57: 1240-1248

Murta, A. G., Pinto, A. L. and Abaunza, P. 2008. Stock identification of horse mackerel (Trachurus trachurus) through the analysis of body shape. Fish. Res., 89: 152-158.

Marques, J. F., Rego, A. L., Costa, J. L., Costa, J. M. and Cabral, H. N. 2006. Genetic and morphological differentiation of the Lustitanian toadfish (Halobatrachus didactylus) between estuarine and coastal areas in Portugal. Sci. Mar., 70: $749-758$

Milione, M. and Southgate, P. C. 2011. Environmental conditions and culture method effects on growth and survival of juvenile winged pearl oyster, Pteria penguin. J. Shellfish Res., 30: 223-229.

Milione, M. and Southgate, P. 2012. Growth of the winged pearl oyster, Pteria penguin, at dissimilar sites in North-eastern Australia. J. Shellfish Res., 31: 13-20.

Naganuma, T., Ogawa, T., Hirabayashi, J., Kasai, K., Kamiya, H. and Muramoto, K. 2006. Isolation, characterisation and molecular evolution of a novel pearl shell lectin from a marine bivalve, Pteria penguin. Mol. Divers., 10: 607-618.

Nie, Z. L., Wu, H., Wei, J., Zhang, X. and Ma, Z. H. 2013. Length-weight relationship and morphological studies in the Kashgarian loach Triplophsa yarkandensis (Day, 1877) from the Tarim River, Tarim River Basin, North-West China. Indian J. Fish., 60: 15-19.

O'Reilly, K. M. and Horn, M. H. 2004. Phenotypic variation among populations of Atherinops affinisi (Atherinopsidae) with insights from a geometric morphometric analysis. J. Fish Biol., 64: 1117-1135.

Orensanz, J. M., Parma, A. M. and Iribarne, O. O. 1991 Population dynamics and management of natural stocks. In: Shumway, S. E. (Ed.), Scallops: biology, ecology and aquaculture, Elsevier, Amsterdam, p. 625-714.

Orensanz, J. M., Parma, M. A., Turk, T. and Valero, J. 2005. Population dynamics assessment and management. In: Shumway, S. E. (Ed.), Scallops: biology, ecology and aquaculture. Elsevier Academic Press, p. 765-868.

Palmer, M., Pons, G. X. and Linde, M. 2004. Discriminating between geographical groups of a Mediterranean commercial clam [Chamelea gallina (L.): Veneridae] by shape analysis. Fish. Res., 67: 93-98.

Poulet, N., Berrebi, P., Crivelli, A. J., Lek, S. and Argillier, C. 2004. Genetic and morphometric variations in the pike perch (Sander lucioperca L.) of a fragmented delta. Archiv Für Hydrobiologie, 159: 531-554. 
Poulet, N., Reyjol, Y., Collier, H. and Lek, S. 2005. Does fish scale morphology allow the identification of population at a local scale? A case study for rostrum dace Leuciscus leuciscus burdigalensis in river Viaur (SW France). Aquat. Sci., 67: 122-127.

Qi, L. J., Huang, Y. L., Zhou, Z. Y. and Zhou, Z. Y. 2011. The growth of the screw dislocation of nacreous layer on Pteria penguin. Sci. China-earth Sci., 54: 951-958.

Rufino, M. M., Gaspar, M. B., Pereira, A. M. and Vasconcelos, P. 2006. Use of shape to distinguish Chamelea gallina and Chamelea striatula (Bivalvia: Veneridae): linear and geometric morphometric methods. J. Morphol., 267: 1433-1440.

Samaee, S. M., Mojazi-Amiri, B. and Hosseini-Mazinani, S. M. 2006. Comparison of Capoeta capoeta gracilis (Cyprinidae, Teleostei) populations in the south Caspian Sea river basin, using morphometric ratios and genetic markers. Folia Zool., 55: 323-335.

Samaee, S. M., Patzner, R. A. and Mansour, N. 2009. Morphological differentiation within the population of Siah Mahi, Capoeta capoeta gracilis, (Cyprinidae, Teleostei) in a river of the south Caspian Sea basin: a pilot study. J. Appl. Ichthyol., 25: 583-590.

Soule, M. E. and Cuzin-Roudy, J. 1982. Allomeric variation. 2. Developmental instability of extreme phenotypes. $\mathrm{Am}$. Nat., 120: 765-786.

Southgate, C. P., Strack, E., Hart, A., Wada, K. T., Monteforte, M., Carino, M., Langy, S., Lo, C., Acosta-Salmon, H. and Wang, A. 2008. Exploitation and culture of major commercial species. In: Southgate, P. C. and Lucas, J. S. (Eds.), The pearl oyster, Elsevier, Amsterdam, p. 303-354.
Silva, A. 2003. Morphometric variation among sardine (Sardina pilchardus) populations from the north-eastern Atlantic and the Western Mediterranean. ICES J. Mar. Sci., 60: $1352-1360$.

Takada, N., Umemura, N., Suenaga, K. and Uemura, D. 2001. Structural determination of Pteria toxins A, B and C, extremely potent toxins from the bivalve Pteria penguin. Tetrahedron Lett., 41: 3495-3497.

Teitelbaum, A., Southgate, P. C., Beer, A., Ngaluafe, P. F. and Finau, M. 2008. Support for Tongan Half-pearl Industry. South Pacific Com. Fish. Newsle. Noumea, 125: 40-44.

Turan, C., Oral, M., Ozturk, B. and Duzgunes, E. 2006. Morphometric and meristic variation between stocks of Bluefish (Pomatomus saltatrix) in the Black, Marmara, Aegean and north-eastern Mediterranean Seas. Fish. Res., 79: $139-147$.

Tzeng, T. D., Chiu, C. S. and Yeh, S. Y. 2001. Morphometric variation in red-spot prawn (Metapenaeopsis barbata) in different geographic waters off Taiwan. Fish. Res., 53: $211-217$

Veasey, E. A., Schammass, E. A., Vencovsky, R., Martins, P. S. and Bandel, G. 2001. Germplasm characterisation of Sesbania accessions based on multivariate analyses. Genet. Resour. Crop Ev., 48: 79-90.

Von, C. T. N., Ling, E. N., Cotter, D. and Wilkins, N. P. 2005. Determination of body shape variation in Irish hatchery-reared and wild Atlantic salmon. J. Fish Biol., 66: 1471-1482.

Wang, Q. H., Shi, S. L., Du, X. D. and Deng, Y. W. 2009. Analysis of morphological difference among three wild populations of Perna viridis. J. Guangdong Oce. Uni., 29: 7-11. 